\title{
Impact of the work in small groups on the educational process in the University of Civil Engineering
}

\author{
Mikhail Leontev ${ }^{1}$ \\ ${ }^{1}$ Moscow State University of Civil Engineering, Yaroslavskoe sh., 26, 129337, Moscow, Russia
}

\begin{abstract}
Researchers and teachers know about the positive impact that cooperation can have on students learning in a small group. It is necessary to clarify how the interaction and cooperation among learners influence the learning process and problem solving in a small group. The objective of the study is to increase the knowledge about the group work in higher education and understand the basis of successful teamwork of students of the university. The study is focused on the concept of student work in small groups in the University of Civil Engineering. Empirical data were collected using specific semi-structured questionnaire and analyzed using qualitative content analysis and special questionnaire. The analysis revealed three variables that influence learning in small groups of students of the University of Civil Engineering: learning process, social function of learning and organization of learning. The author revealed the correlation between these variables and the final result of learning (increase or decrease of the effectiveness of learning), as well as between these variables and the presence of positive or negative work experience in a small group.
\end{abstract}

\section{Introduction}

The work in small groups is used as a tool for learning at all levels in the majority of educational systems. The main goal of the work is to serve as a stimulus for learning. That is noted in studies aimed at improving the effectiveness of group work and understanding the benefits of certain types of group work. R.M. Gilles, T. Doyle, A.D. Ishkov argued that the growing interest in this topic can be noticed in the fact that the researches and teachers are aware about the positive impact of cooperation on learning capacity in some types of group work. The main problem in this field of research was to determine how the interaction and cooperation among learners affect learning and problem solving in a small group $[1,2,3]$.

The objectives of the study are to increase knowledge about the group work in higher education and understanding what is the basis of successful teamwork of students of the university. The study focused on the experience and concept of work in small groups and learning in small groups of students of the University of Civil Engineering. 
Two approaches relating to learning in a small group are the subject of interest, namely, joint learning and education through cooperation. J. Michael, B. Oakley et al. have claimed, that working together in small groups is usually considered as a complex, generalized activity on the basis of several active working modes of learners, while the cooperation is a narrower concept, that can be included in the broader concept of teamwork. Joint learning can mean group work without any interaction between learners (for example, learners can simply be near each other) $[4,5]$, but cooperative learning is always involves interaction, cooperation and the use of group competence.

At present, A. Shnyrenkov and I.P. Pryadko affirm that there is considerable support for learning and work in small groups of learners in the scientific literature [6] and regulations [7]. In addition, M. Laal et al. said that cooperative learning promotes academic achievement and desire for interaction. Working in a small group in interaction mode, students learn new information, share ideas, clarify differences, solve problems and create new understanding. Learners, working together, are more motivated to achievement than when working alone. However, the studies of the processes occurring in small groups for their work, and what factors actually affect the ability to learn, are still not enough, especially when it comes to the learners' point of view [8]. In addition, the question - why some kinds of work in a small group are successful and others are on the contrary - has not yet been resolved. In this article, we hope to contribute to an understanding why some small groups show a positive learning experience and work, while others show the opposite results.

The work in a small group in higher education can serve different purposes. The learning process can take place in traditional forms or in working groups. Work place, place of communication and social security can be equally important for academic excellence, and as a prerequisite for social learning. Thus, a small group and work in it carry out more features than are "simple" pedagogical form of learning. Without taking into account the advantages and disadvantages of group work, the non-reflexive choice of learning forms and teaching tools could eventually lead to less desirable consequences. The reflective choice may promote the acquisition of positive experience and success in education [9].

From the perspective of the learning process, the work in a small group may be as the goal (i.e., learning the skills of teamwork), considered mean (for example, the basis for academic achievement), or both. If the group work is considered as a goal, the group functions are to promote the development of learners' skills in a small group, such as social learning and interpersonal skills. If the work in small groups is considered as a mean of gaining knowledge and skills, groups and cooperation in groups become the basis for the acquisition of knowledge and skills by learners [9].

Small group can be considered as educational environment when working in a group is used as a purpose and as a mean, for example, groups of problem-based education. Even if group work is defined as a work of learners together in a group or team, it is important to keep in mind that group work usually combines several types of activity in different conditions of interaction. This means that the group work can change its characteristics several times during the session of group work and/or during the life of a small group, so that the operating modes may vary in different stages of the work in a group. N. Davidson, C.H. Major argued if the main condition for effective work in a small group is cooperation, this work has a number of advantages: 1) opportunity for group members to learn from each other; 2) increasing importance of personal contribution of each group member; 3) the possibility of combining different perspectives and skills to solve problems; 4) mutual support; 5) the opportunity for group members to inspire and motivate each other [10].

However, work in small groups has some disadvantages that reduce the effectiveness of implementation of a group task. Among the problems that complicate the work in a small group, are: 1) competition and jealousy; 2) the phenomenon of groupthink; 3) disputes 
between group members; 4) obvious personal antipathy of participants; 5) group members do not recognize the leader; 6 ) leader is not able to manage the group: there is the resistance on the part of some participants that interferes or refuses to act together; 7) weakening of motivation for group activities. The small group should not include mutually rejecting learners.

It is also important to distinguish how people work in a small group. There are two basic ways of cooperation in groups: group work (together) or work as a joint group (in cooperation). Situations in which learners are collected together but work individually, performing specific tasks for the group, mean group work, it is usual for institutions of higher education [10]. Cooperation between learners here can take place, but it is not necessary for achievement the goals of small groups. At the end of the assignment, the learners combine their results in the form of the overall product. Joint actions are not required, but mutual learning can take place. Notwithstanding, in this case, the benefits are due to the social facilitation and are not caused by cooperation. Social facilitation increases motivation in this situation due to the fact that the presence of others affects the productivity of individual learner.

Work as a joint group, on the other hand, will reflect the benefits of learning through collaboration with other members of the group. That means, learners use the skills of the group members in this work and work together for the achievement a common purpose. In addition, work as a joint group implies a partnership, all group members are included in a job, working for a common cause, for a common result. Work as a unified group is characterized by joint efforts, using the group competence, finding problem solving and reflection. This is an unusual activity in higher education institutions. Both approaches can be useful in different stages of group work, depending on the purposes of the work of small group and the type of task, given to a group.

There are limited number of studies on the approaches to group work. Various aspects of good practice have been identified. For example, A.D. Ishkov affirmed that there was identified the need for all people to participate and make an effort to group work, to establish clear objectives for work [13]. There was a role differentiation among participants, the task was actual, there was a clear leadership.

Combined knowledge of students and researchers has been summarized in the context of a common point of view on the group work. As a result, students and researchers outlined that the following conditions for the ideal group work were important: a) group work is carried out in favorable situations, b) there is cooperation, c) group work could be well structured, d) learners come prepared and work during the sessions, e) participants demonstrate respect for each other. Obviously, it acquires more systematic study of the concepts and practices of group work of students. This study is a step in this direction.

\section{Materials and Methods}

The choice of research methods was due to the achievement of the understanding what is the basis of successful work in small groups of the students. It is necessary to study the experience and the concept of work in small groups and learning in small groups of students of the University of Civil Engineering. It is necessary to give students the opportunity to speak out on the issues, to find out their point of view, the way they evaluate learning during the work in small groups. In addition, it is important the opinions of students about the issue why some of the results of work in a small group have a positive effect and contribute to learning, and why the result is opposite in other cases.

The inductive qualitative approach was used to capture the experience of students of the University of Civil Engineering and the concepts of group work. Empirical data were collected using a specifically structured questionnaire. The qualitative analysis was held. 
All learners involved in the study were learned on the university programs. In the programs group work was a pivotal and commonly used teaching method. Students of the programs, that used specific pedagogical approaches, were not included in the study.

The study involved 190 volunteer undergraduate students, 104 male and 86 female, from the ISA and EUIS institutes of NIU "MGSU". Students enrolled were learned on the profiles: "Architecture", "Construction", "Standardization and Metrology", "Computer Science and Engineering". Comparative analysis has been carried out on the basis of the survey. Respondents were learned for eight semesters, most of them had experience of working in a small group in other conditions. Small groups consisted of 4-8 students, were of heterogeneous gender in most cases. Members of small groups did not work together before, during educational process. Special structured questionnaire was developed to collect data on the experiences and concepts of group work of learners. It was close to the students' experience in the work of particular group. The questionnaire contained 22 questions, including points with multiple-choice answers and open-ended points. The questionnaire was distributed among different groups of students (some groups were learned on the same profile).

\section{Results}

Experimental data were analyzed using qualitative content analysis based on the three research questions: (1) How the work in a small group contributes to your education? (2) What is the positive experience you get while working in the group? (3) What is the negative experience you get while working in the group? Each question matches to one aspect of the purpose of the research.

The analysis was conducted in several stages, with three phases in each stage: preparation, organization and reporting. Each question was considered as a unit of analysis. Statistical analysis revealed three main variables: learning process, social function of learning and organization of learning. Each variable corresponds to the positive aspects of the experience (which facilitates the process, social function, and/or organization of learning), as well as the negative alternative. There were not found any differences by gender in the distribution of positive and negative aspects of the experience on the different variables, neither on the educational profiles, nor the distribution of negative experiences (at $\mathrm{p}>0,06)$. At the same time, there were differences between the educational profiles and the distribution of positive experience $\left(\chi^{2}=14,423\right.$; DF:6; $\left.p<0,022\right)$. $\left(\chi^{2}-\right.$ «Chi-squared», $\mathrm{DF}$ - number of degrees of freedom, $\mathrm{p}$ - significance level) [12]. Students enrolled in "Architecture" displayed larger number of positive practices in connection with the learning and social function and organization of learning compared with other educational programs. The gender or institute were not influenced on the results. However, when comparing the four educational profiles included in the study, and types of education, there was a difference $(\chi 2=13,739$; DF: $6 ; p<0.03)$. On the one hand, students on educational profiles "Construction" and "Standardization and Metrology" emphasized academic knowledge. At once, students on educational profiles "Architecture" and "Computer Science and Engineering" frequently mentioned the possibility of joint learning without assistance, in addition a combination of academic knowledge and learning in groups.

\section{Discussion}

The explanation of the results obtained could be due the fact that the types of tasks for students varied in different educational programs. That may be related to both the purpose of group work (work in a small group as a purpose or as a mean), as well as to the 
organization of learning (work in a group or as a joint group/team). Another possible explanation may be the following: the emphasis on the educational profiles, "Construction" and "Standardization and Metrology", is made on academic knowledge, while the learning process is more clearly formulated and claimed the group modalities on the other two profiles.

Despite the fact that the participants did not directly report that work in small groups makes it more difficult to learn, they often mentioned that consider the group work as unproductive by reason of losing concentration and the presence of conflicts impeding learning. Group work can be perceived as inefficient and time-consuming, taking into account the long periods with tiresome discussions.

The presence or absence of conflicts in a group influenced the students' experience, and unmanaged conflicts more likely negatively affected to learn, which corresponds to the opinion of B. Payne et al. [13]. Students understood that it is difficult to come to the terms and get result of group work because of conflicts, so conflict-free environment considered important stimulus for learning.

Working in a small group also had an important function of social learning, the students characterized the participation in groups as an important factor of affiliation. Many participants also reported that they felt positive psychological atmosphere in the group. Belonging to a group also influenced the motivation of students to learn and achieve results. It is shown that the total time spent on the work and efforts might be increased. By group work, participants also received a confirmation of their status and opportunities.

Many students said that the atmosphere in small groups and group processes could be a source of negative feelings and experience: for example, when there was not enough time to know each other better, or when students were in situations without joint actions for long time. Examples of negative experiences were leaving of participants from the overall process due to difficulties in communication, ambiguity in roles, misunderstanding with other participants. Students on profile "Architecture" pointed larger number of good practices in connection with the function of social learning and organization of learning compared with students on the other profiles.

Organization of group work includes aspects that are actual regardless of how students perceive teamwork, positive or negative, which is consistent with the views of H. Shipton [14]. In difference to the learning process and function of social learning, organization of learning includes the same aspects regardless of working experience of learners, especially, composition of group, group structure, work methods and contributions to work.

If the group composition is diverse (heterogeneous), it is likely the experience are acquired in the positive and negative sense. The heterogeneous group composition can be perceived positively, as learners can assume that they have similar life situations, views and skills, and they have favorable conditions for cooperation in the group. Effectively working small groups are characterized by developed methods of joint activities [15], while the other groups have not enough cooperation. Some participants see a positive role in the pressure of environment.

Contribution of learners to working in groups is a key factor for understanding of the work in a small group. Groups work productively, if all participants contribute to their work, but the sense of contribution may differ in dependence of the qualifications of participants. The same conditions may lead to the opposite result, i.e. interfere the learning and intensify the negative experience. If the group composition is identical (homogeneous), it can lead to uniformity of opinion, that some participants perceive as negative. If the group is regarded as too small or large, the learners seem to see this as a disadvantage too.

Disadvantages of the group structure can lead to a low degree of satisfaction with the work methods of the group. The general expressed view was seen in the students' 
responses. The work in a small group is often seemed as poorly structured in the case of: absence of students, unprepared or insufficiently prepared students for group work.

Important characteristic of small groups with low productivity was indicated. The contribution to the work of such groups differs between the participants. If a small group gathered together participants with different levels of claims, it could lead to different levels of involvement and responsibility to work, as well as it manifested differences in the willingness to accept responsibility or part of the work in the process of group work. Some participants were active and did a lot of work, while others hardly did anything.

\section{Conclusions}

The study focused on the aspects of group work and education in small groups of students of the University of Civil Engineering. The analysis revealed three variables: learning process, social function of learning and organization of learning, influenced on the learning in small groups. The results reflect the relationship between these variables and the educational result (increase or decrease the effectiveness of learning), as well as the presence of positive or negative work experience in a small group. All three variables can help or hinder learning, and the acquisition of work experience in a small group.

There are some limitations to this study, and most of them are related to the worked out structured questionnaire. Firstly, the questions do not make a distinction between: a) the type, b) the purpose, c) the structure of the work in a small group (i.e. involvement and/or time), d) working methods in a small group (cooperation and collaboration). Secondly, the questionnaire design is such that it is considering a job in a small group as a unified activity and does not recognize that the group work can perform different tasks and include a variety of activities. This simplification of work specifics in a small group may cause criticism. Worked out description of analysis and comparison of the three variables acted as a counter-argument, it became possible to join the results into common array.

The results obtained by analyzing students' experience, showed that the work in a small group facilitates the learning process, especially with regard to the academic knowledge. Three important variables (learning process, social function of learning and organization of learning) for group work, which increase the efficiency of educational process and are incentives for learning, have been identified and discussed. Taking into account the opinion of the students, their experience and views, we can offer new knowledge and knowing of what is, in fact, behind the successful work in a small group in the University of Civil Engineering. In addition, the students' explanations about why some of the results of group work are reflected in the positive experience and learning, and in other cases the result is opposite, may be useful for further researches of problem of working in a small group in pedagogical practice.

\section{References}

1. R.M. Gilles, A.F. Ashman, Co-operative Learning. The social and intellectual outcomes of learning in groups ( N-Y., 2003)

2. T. Doyle. Helping students learn in a learner-centered environment: A guide to facilitating learning (Sterling, VA: Stylus Publishing, 2008)

3. A.D. Ishkov, M.G. Leontev, Procedia Engineering, 117, 142-147 (2015)

4. J. Michael, Advances in Physiological Education, 30, 159-167 (2006)

5. B. Oakley, R.M. Felder, R. Brent, 2(1), 9-34 (2004) 
6. E.A. Shnyrenkov, I.P. Pryadko, Procedia Engineering, 117, 325-330 (2015)

7. Russian Federal Law from 29.12.2012 № 273-FZ (rev. from 02.03.2016), Education in the Russian Federation"

8. M. Laal, S.M. Ghodsi, Procedia - Social and Behavioral Sciences, 31, 486 - 490 (2012)

9. N.A. Shukor, Z. Tasir, H. Van der Meijden, J. Harun, Journal of Educational Technology \& Society, 17(4) , 216-228 (2014)

10. N. Davidson, C.H. Major, Journal on Excellence in College Teaching, 25(3, 4) 7-55 (2014)

11. A.D. Ishkov, Procedia - Social and Behavioral Sciences, 142, 54-58 (2014)

12. D.C. Howell. Statistical Methods for Psychology, (Cengage Learning, Wadsworth, 2013)

13. B. Payne, M. Sumter, E. Monk-Turner, Academic Exchange Quarterly, 9(2) , 22-26 (2015)

14. H. Shipton, D. Fay, M. West, M. Patterson, K. Birdi, Management, 14(2) 118-128 (2005)

15. A. Burke, Journal of Effective Teaching, 11(2), 87-95 (2011) 